\title{
EXPERIMENTAL STUDY ON A NEW PRECAST UNBONDED POST-TENSIONED BEAM-COLUMN JOINT SYSTEM WITH SHEAR BRACKET
}

\author{
新しいアンボンド PC-PCa 柱梁接合部実験に関する研究
}

\author{
Do Tien THINH*1 ${ }^{* 1}$ Koichi KUSUNOKI*2 and Akira TASAI*3 \\ ドティエンティン，楠＼cjkstart浩一，田才＼cjkstart晃
}

\begin{abstract}
In this study, new type of precast unbonded post-tensioned exterior beam-column joint of a long span frame was proposed and tested under the simultaneous action of gravity and cyclic load. The connection was designed with shear bracket to resist the shear force induced by the gravity load and post-tensioned steel to resist moment and shear force due to the earthquake load. The design concept is to control the deformation due to the earthquake load by accepting the opening between the beam and column interface in order to keep away from the damage to the beam and the column. The test results showed efficient seismic behaviors with minor cracks occurred in the beam and column, good self-centering behavior and small beam slip.
\end{abstract}

Keywords: Shear bracket, Unbonded, Post-tensioned, Precast concrete, Exterior connection, せん断ブラケット，アンボンド，ポストテンション，プレキャストコンクリート，外接合部

\section{INTRODUCTION}

Up to now, precast concrete buildings were not commonly used in Japan, and most of them were applied for apartment buildings. In the office buildings, which require wide space and thus long span, precast concrete was rarely used. The design philosophy for precast concrete moment resisting frame buildings depends on cast-in-place approach to provide equivalent performance with monolithic connections ${ }^{1}$. The precast elements were connected together by cast-in-place concrete, thus advantages of precast concrete such as cost-effective, well-controlled quality, and fast, easy erection on site, are greatly reduced. Moreover, current precast and cast-in-place concrete buildings may also suffer from heavily damage at the plastic hinge region during a major earthquake.

Recently, new design philosophy was developed to overcome this obstacle for precast concrete moment resisting frame. In this philosophy, the connections are detailed to be weaker than the precast elements and are allocated as location of ductile inelastic deformation to be occurred.

With this new philosophy, former studies have been developed and tested the ductile connection type with unbonded post-tensioned steel. However, the test specimens in these studies just simulated small to medium span frame and no gravity load was applied to the beam to reproduce the actual condition ${ }^{4) ~ 77)}$.

In this study, new type of ductile precast connection, in which post-tensioned steel resists the moment induced by seismic and gravity loads, and shear bracket resists the shear force induced by the gravity load, was proposed and tested. The object of this study program was the exterior connection in upper stories of a long span frame precast building, in which the moment and shear force induced by the gravity load were much larger than that of the seismic load. The requirements of the connection were well performing, easy and rapid erecting and disassembling. In order to investigate the performance of the connection, gravity load was applied simultaneously with the cyclic load. The effect of topping slab and spandrel beam on the behavior of the connection was also investigated.

\section{TEST PLAN}

2.1 Specimens outline
${ }^{* 1} \mathrm{Ph}$. D. Student, Dept. of Architecture, Faculty of Engineering, Yokohama National University, M. Eng.

* 2 Assoc. Prof., Dept. of Architecture, Faculty of Engineering, Yokohama National University Dr. Eng.

* 3 Prof., Dept. of Architecture, Faculty of Engineering, Yokohama National University, Dr. Eng.

\author{
横浜国立大学大学院工学研究院 大学院生 $\cdot$ 工修 \\ 横浜国立大学大学院工学研究院 准教授・博士(工学) \\ 横浜国立大学大学院工学研究院 教授・工博
}


The test specimens represented the exterior beam-column connection at the $10^{\text {th }}$ floor of a prototype twelve-story precast frame office building, of which story height is 4 meters, and the span length is 18 by 7.2 meters. The frame columns and beams sections were 800 x $800 \mathrm{~mm}$ and $600 \times 1000 \mathrm{~mm}$, respectively. The main structural system of the building is precast unbonded post-tensioned frame. For this building, the safety limit is designated as maximum drift angle should not exceed $2 \%{ }^{9}$. There were totally four specimens in this study. The first, named SB was designed with shear bracket that resisted the shear force induced by the design gravity load of $255 \mathrm{kN}$. The second, named SF was designed without shear bracket to investigate the shear friction behavior under the simultaneous effect of gravity and cyclic load, and to compare to other specimens that have shear bracket. The third, named SB-L, was designed with shear bracket to resist the shear force induced by the gravity load of $382.5 \mathrm{kN}, 1.5$ times of that of specimen SB. This gravity load corresponded to longer span frame. The fourth, named SB-S, was designed similar to specimen SB, but had the slab and spandrel beam to investigate the effect of the slab on the behavior of the connection. Due to the constraint of the testing system, test specimens were scaled down to half of the prototype and the beam was shortened. The specimens were designed following ductile connection philosophy in which flexural and the shear strength of the beams and columns were higher than that of the connection.

The demand moment and shear force at the beam end were 86 $\mathrm{kNm}$ and $288 \mathrm{kN}$, respectively. In the specimen $\mathrm{SF}$, the prestressing steel (hereafter referred to as PC) bars were designed to resist the total demand moment and shear force, while in the other specimens, the shear force induced by the gravity load was carried by the shear bracket, and the PC bars were designed to resisted the demand moment and shear force induced by the cyclic

Table 1 Specimens outline

\begin{tabular}{|c|c|c|c|c|c|}
\hline \multicolumn{2}{|c|}{ Specimens } & SB & SF & SB-L & SB-S \\
\hline \multirow{9}{*}{ Beam } & Section $(\mathrm{mm})$ & \multicolumn{4}{|c|}{$300 \times 500$} \\
\hline & $F_{c}\left(\mathrm{~N} / \mathrm{mm}^{2}\right)$ & 60.4 & 60.4 & 60.4 & 60.4 \\
\hline & $f_{y}\left(\mathrm{~N} / \mathrm{mm}^{2}\right)$ & 337.7 & 337.7 & 337.7 & 337.7 \\
\hline & $f_{W y}\left(\mathrm{~N} / \mathrm{mm}^{2}\right)$ & 329.3 & 329.3 & 329.3 & 329.3 \\
\hline & PC steel & $\begin{array}{c}2-\phi 15 \text { SBPR } \\
\text { Grade C }\end{array}$ & $\begin{array}{c}2-\phi 26 \text { SBPR } \\
\text { Grade A }\end{array}$ & $\begin{array}{c}2-\phi 15 \text { SBPR } \\
\text { Grade C }\end{array}$ & $\begin{array}{c}2-\phi 15 \text { SBPR } \\
\text { Grade C }\end{array}$ \\
\hline & $\sigma_{0}\left(\mathrm{~N} / \mathrm{mm}^{2}\right)$ & 1.93 & 4.07 & 1.93 & 1.91 \\
\hline & $N / P_{y}$ & 0.7 & 0.7 & 0.7 & 0.7 \\
\hline & PC length $(\mathrm{mm})$ & 1500 & 1500 & 1500 & 1500 \\
\hline & Bracket, $h \times t(\mathrm{~mm})$ & $120 \times 25$ & none & $140 \times 32$ & $120 \times 25$ \\
\hline \multirow{4}{*}{ Column } & Section $(\mathrm{mm})$ & \multicolumn{4}{|c|}{$400 \times 400$} \\
\hline & $F_{c}\left(\mathrm{~N} / \mathrm{mm}^{2}\right)$ & 60.4 & 60.4 & 60.4 & 60.4 \\
\hline & $f_{y}\left(\mathrm{~N} / \mathrm{mm}^{2}\right)$ & 386.2 & 386.2 & 386.2 & 386.2 \\
\hline & $f_{W y}\left(\mathrm{~N} / \mathrm{mm}^{2}\right)$ & 329.3 & 329.3 & 329.3 & 329.3 \\
\hline \multirow{4}{*}{ Slab } & Existence & none & none & none & yes \\
\hline & Thickness (mm) & - & - & - & 100 \\
\hline & $F_{c}\left(\mathrm{~N} / \mathrm{mm}^{2}\right)$ & - & - & - & 60.9 \\
\hline & $f_{S y}\left(\mathrm{~N} / \mathrm{mm}^{2}\right)$ & - & - & - & 410.2 \\
\hline
\end{tabular}
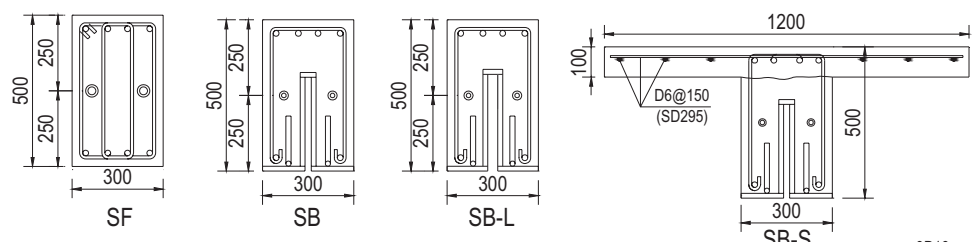

A-A Section

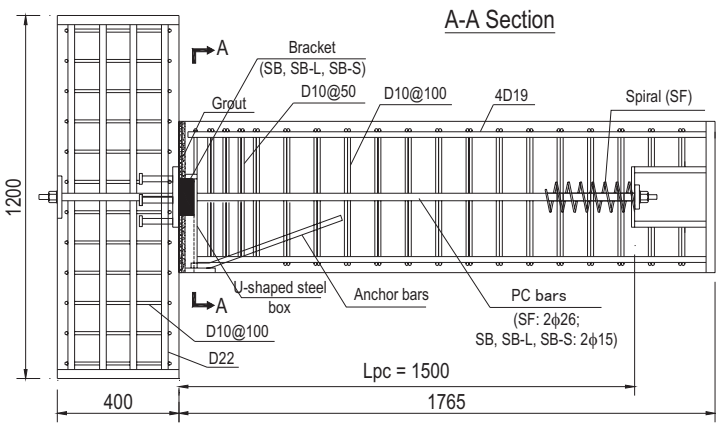

Figure 1 Reinforcement details of the specimens

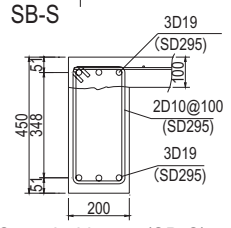

Spandrel beam (SB-S)

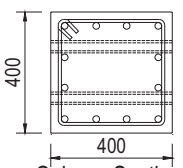

column Section
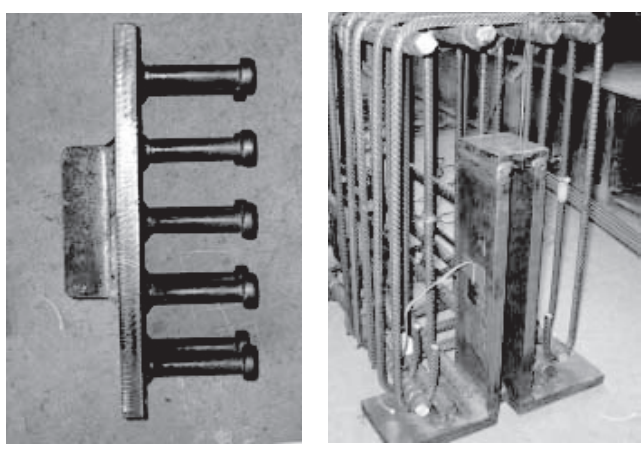

Figure 2 Shear bracket and inverted U-shaped steel box 
load.

In the specimen SF, shear force from the beam was transferred to the column by shear friction at the beam-to-column interface. The required volume of PC bars was calculated as follows:

$$
N=\frac{Q}{\mu}
$$

where: $N$ is the total initial prestressed force, $N=0.7 P_{y}, P_{y}$ is the yield load of the PC steel, provided by the manufacturer, $Q$ is the total shear force at the beam end, and $\mu$ is the friction coefficient, $\mu$ of 0.5 was applied according to the AIJ guideline ${ }^{2}$. Applied $2 \phi 26$ SBPR Grade A PC bars with the yield load of $417 \mathrm{kN}$ x $2=834 \mathrm{kN}$, corresponding yielded moment strength was $M_{y}=$ $187.7 \mathrm{kNm}$, satisfy to resist demand moment of $86 \mathrm{kNm}$.

In the specimens SB, SB-L, and SB-S, $2 \phi 15$ SBPR Grade C PC bars with the yield load of $191 \mathrm{kN}$ x $2=382 \mathrm{kN}$ were used. Corresponded moment and shear strength were $86 \mathrm{kNm}$ and $133.7 \mathrm{kN}$, respectively. It can be seen that, with the existence of the shear bracket, the required volume of the PC bars was reduced about $50 \%$. The $\mathrm{PC}$ bars were arranged at the middle level of the beam to delay the yielding of the PC steel at large drift level.

The shear bracket was designed as a simple corbel welded to a steel plate that embedded into the column. Shear strength of the bracket was calculated as:

$$
Q_{s}=0.9 \frac{F_{y}}{1.5 \sqrt{3}} a_{w} \geq Q_{L}
$$

where: $Q_{s}$ is the shear strength of the bracket, $F_{y}$ is the yield strength of the steel plate, $a_{w}$ is the vertical shear resistance area, $a_{w}=h t$, where $h$ and $t$ are the height and thickness of the bracket, respectively, and $Q_{L}$ is the shear force at the beam end induced by the gravity load.

The bracket with the dimensions of $120 \times 19 \mathrm{~mm}$ was applied for specimens SB and SB-S, while the $140 \times 32 \mathrm{~mm}$ bracket was applied for specimen SB-L.

The length of the shear bracket $l_{s}$ is determined so that at the designated maximum rotation of the beam, the beam will not be out of the bracket and be calculated as:

$$
l_{s}=R \times 0.4 D+b_{m}+l_{t}
$$

where: $R$ is the maximum designated beam end rotation, $D$ is the beam height, $b_{m}$ is the grout thickness, and $l_{t}$ is the manufacture tolerance.

The bracket was welded to a steel plate which connected to the studs. The studs were designed to resist the shear force and moment transferred from the beam ${ }^{3)}$. At the beam end area, in order to transfer the shear force and moment to the bracket and to prevent the concrete from compressive failure, an inverted U-shaped steel box was applied. Outline of the specimens is shown in Table 1. The sectional dimensions and reinforcement details of the specimens are shown in Figure 1 and the photos of the bracket and inverted U-shaped steel box are shown in Figure 2.

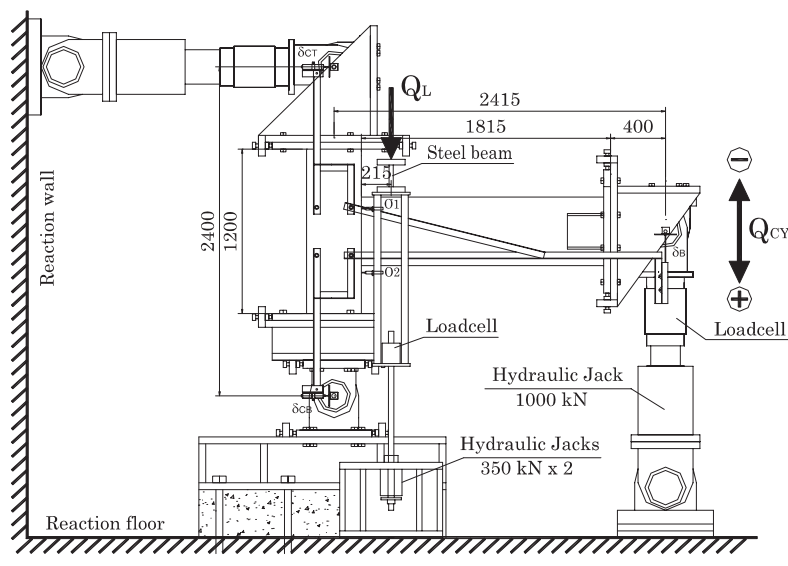

Figure 3 Test setup

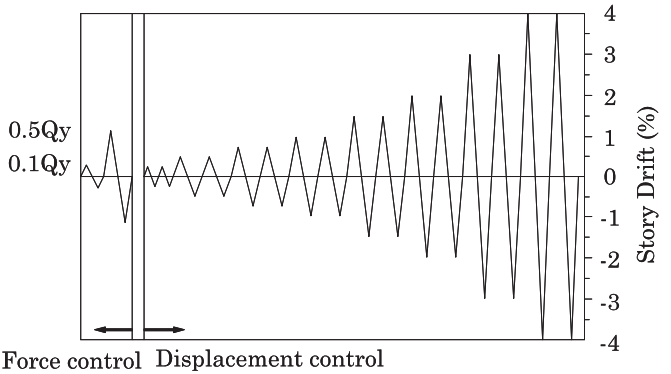

Figure 4 Loading history

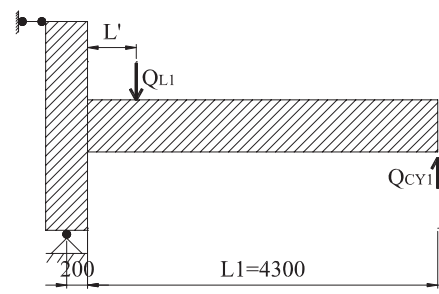

a) Original model

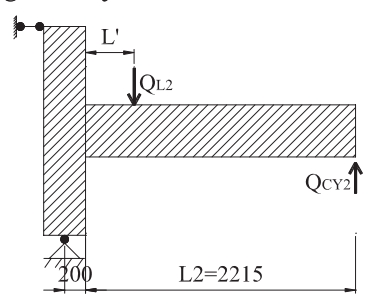

b) Actual specimen
Figure 5 Illustration of the terms in the Equation (4)

\subsection{Specimens construction}

After being separately cast, the beams and columns were assembled, and the $20 \mathrm{~mm}$ tolerance space between the beam and the column face was filled by the grout. A steel mesh was used to reinforce the grout and prevent it from spalling down at high drift level. For specimen SB-S, the slab was cast 9 days after the beam was cast and unified with the beam. The slab reinforcements were connected to the spandrel beam but not the column. High strength PC bars were used to join the beam to the column. The prestressing force was applied 21 days after casting the beams and columns.

\subsection{Test setup and testing sequence ${ }^{8)}$}

\section{(1) Experimental setup}

The experimental setup is shown in Figure 3. The lower end of the column was connected to the reacting floor by the pin while the upper end was connected to the reaction wall by horizontal two-end pin brace that is equivalent to a vertical roller. The cyclic load was applied to the beam end by the $1000 \mathrm{kN}$ hydraulic jack 
that attached to the beam end with the pin. The gravity load was applied to the beam as a concentrated vertical load at the distance of $215 \mathrm{~mm}$ from the column face.

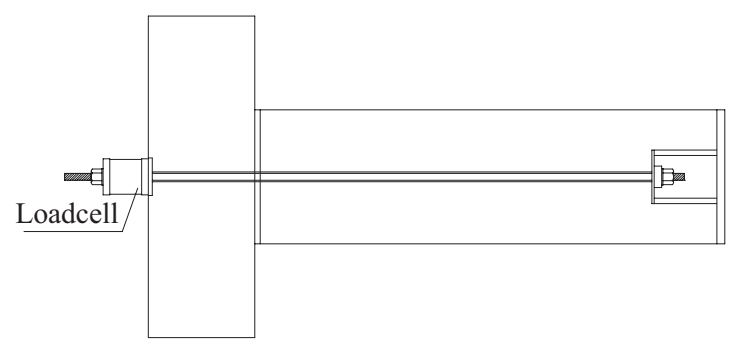

Figure 6 Measuring of the tensile force of prestressing steel

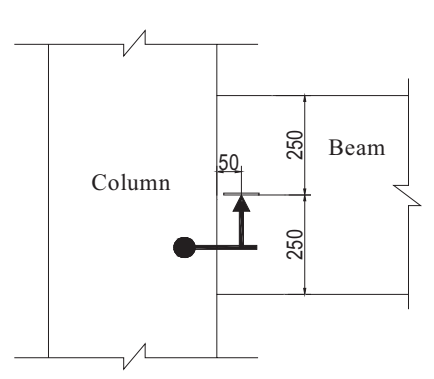

a) Measurement system

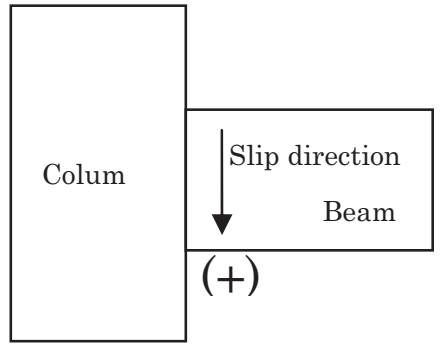

b) Sign convention of beam slip
Figure 7 Measurement system and sign convention for the beam slip (2) Loading history

The loading history is shown in Figure 4. The specimens were tested under simultaneous action of cyclic and gravity load. First, the gravity load was applied gradually to designated value, and then the cyclic load was applied. As mentioned before, the beams of the specimens were shortened from $4.3 \mathrm{~m}$ to $2.215 \mathrm{~m}$, hence, in order to generate the same combination of moment and shear force at the beam column interface as in original condition; the gravity load was controlled according to the original gravity load $Q_{L 1}$ and the cyclic load $Q_{C Y}$ as:

$$
Q_{L}=Q_{L 1}+\left(\frac{L_{2}-L_{1}}{L_{1}-L^{\prime}}\right) Q_{C Y}
$$

Where: $Q_{L 1}$ was the original gravity load, $L_{1}$ was the original beam length, $L_{1}=4.3 \mathrm{~m}, L_{2}$ was the new beam length, $L_{2}=2.215 \mathrm{~m}$, the beam length was considered up to column face, $L^{\prime}$ was the distance from the gravity load to the column face, $L^{\prime}=0.215 \mathrm{~m}, Q_{C Y}$ was the cyclic load. $Q_{C Y}$ has the same sign with $Q_{L}$ if they act on the same direction, and vice versa. These terms are shown in Figure 5. For the cyclic load, the first two cycles was loaded by the force control, of which the peak values were $0,1 \mathrm{Q}_{\mathrm{y}}$ and $0,5 \mathrm{Q}_{\mathrm{y}}$, where $Q_{\mathrm{y}}$ is the story shear force that corresponded with yielding of the PC bars. After that, displacement control was used with the peak displacements of $0.25 \%, 0.5 \%, 0.75 \%, 1 \%, 1.5 \%, 2 \%, 3 \%$, and $4 \%$ story drift. Two cycles were carried at each story drift level.
After the drift of $4 \%$, the cyclic load was applied up to $6 \%$ story drift in positive direction. As shown in the Figure 3, the cyclic load is assigned as positive when it causes the beam top fibers in tension.

(3) Data acquisitation system

The gravity load, cyclic load, and PC bars force were measured by the loadcells. In order to measure the tensile force of prestressing steel, loadcells were directly attached to PC bars as shown in Figure 6. The loadcells were maintained continuously from the time of applying prestressing force to the end of the test. The story drift was measured by the rigid frame, which was attached to the top and bottom pin of the column and the transducers were fixed to the frame to measure vertical displacement of the beam end. The opening of the beam-to-column interface, vertical slip of the beam, and the deformation of the beam and column were also measured. In order to measure the slip of the beam, a transducer was fixed on the column in vertical direction, while the target was fixed on the beam at the mid height position as shown in Figure 7. The slip was designated as positive when the beam goes downward relative to the column. Strains of the PC bars, four beam stirrups closest to the column face, four hoops of the column within the joint, column longitudinal bars, and the inverted U-shaped steel box were measured.

\section{TEST RESULTS AND DISCUSSIONS}

\subsection{Visual Observation}

The crack patterns of the beam and column around the joint of the specimens at $4 \%$ drift are shown in Figure 8 . In all specimens, very few minor flexural cracks occurred in the beams as well as the columns. There were some shear cracks occurred in the joint, but their width was less than $0.1 \mathrm{~mm}$. The number of cracks was largest in the specimen without shear bracket (SF), and fewer in other specimens with shear bracket. In the specimen SF, the cracks developed from joint area near the top and bottom of the beam to the mid-height of the joint at the opposite side. It should be noted that the prestressed force in the specimen SF was about two times larger than those in other specimens, hence the reaction force from the top and bottom of the beam react on the column joint also larger. This resulted in larger tensile stress in the compressive strut within the joint, then more joint cracks in the specimen SF than in other specimens.

In the beam end area near column face of the specimen SB, SF, SB-L, there were some inclined cracks occurred at the top-half, while there was no crack occurred at the bottom. These cracks might result from the combination of compressive and shear stress induced by the cyclic and concentrated gravity load. The concrete at the top edge and the grout at the bottom edge of the beam started to be crushed at the drift of $3 \%$ and $2.0 \%$ for the specimens SB and SB-L, $1.5 \%$ and $1.0 \%$ for the specimen SF, and 


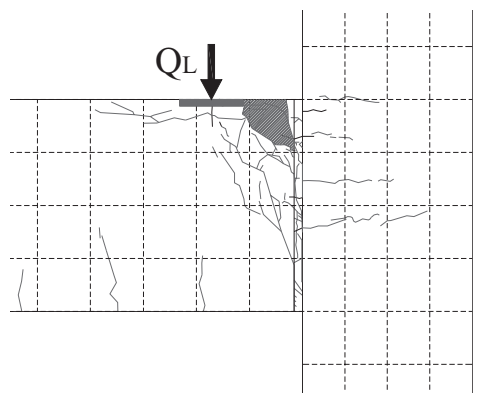

a) $\mathrm{SB}$

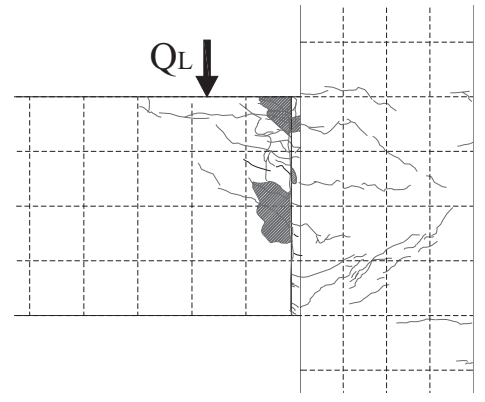

b) $\mathrm{SF}$

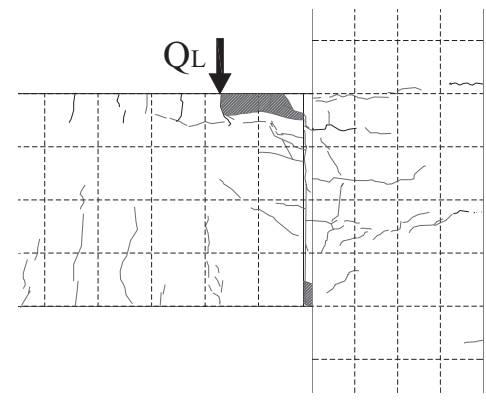

c) SB-L

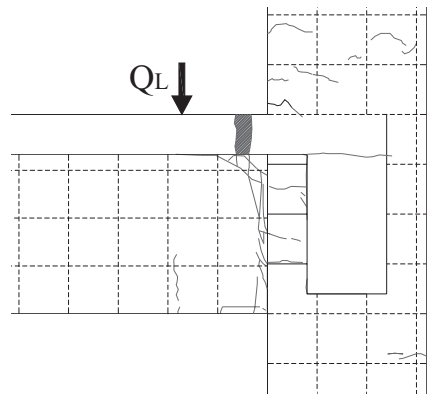

Beam and column

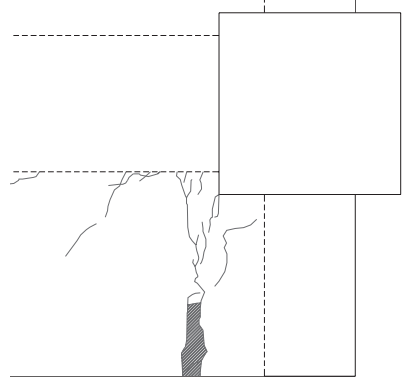

Slab (bottom)

d) SB-S

Figure 8 Crack patterns of the specimens at $4 \%$ drift

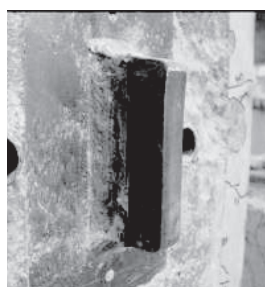

a) $\mathrm{SB}$

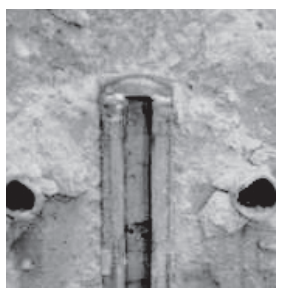

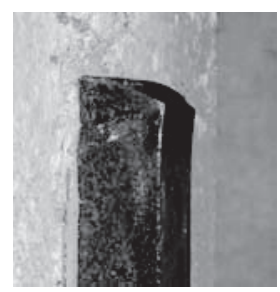

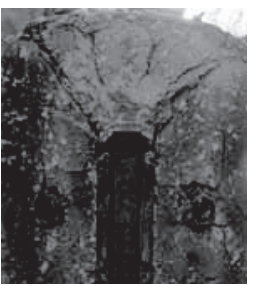

b) SB-L

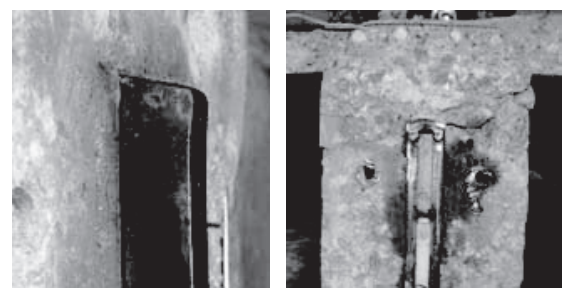

c) SB-S

Figure 9 Shear bracket and U-shaped steel box at the end of the test

$1.5 \%$ and $1.5 \%$ for the specimen SB-S, respectively. The concrete at the mid-height of the beam at the position of the PC bars spalled at the drift of $3 \%$ in the specimen SF. The slab concrete fell down at the drift of $3 \%$. The widths of the opening at the drift of $4 \%$ in positive and negative moment were $18.5 \mathrm{~mm}$ and $21 \mathrm{~mm}$ for the specimen $\mathrm{SB}, 14.5 \mathrm{~mm}$ and $18 \mathrm{~mm}$ for the specimen $\mathrm{SF}, 16 \mathrm{~mm}$ and $14 \mathrm{~mm}$ for the specimen SB-L, $19 \mathrm{~mm}$ and $17.8 \mathrm{~mm}$ for the specimen SB-S, respectively. In the specimen SB-S, the number of these cracks was much less than in other specimens, as a result of the existence of the slab. Because the slab was cast to be unified with the beam and spandrel beam, and the slab reinforcements were anchored to the spandrel beam, the slab concrete was heavily damaged (Figure 8d).

Shear bracket and the inverted U-shaped steel box of the specimens SB, SB-L, and SB-S after tested are shown in Figure 9. In all specimens, no damage was observed in the shear bracket and the concrete around it. However, the top of the bracket was deformed. The bracket could resist the beam even at the drift up to $6 \%$. The inverted U-shaped steel box at the beam end was designed to transfer the shear force from the beam to the shear bracket on the column. In specimens SB and SB-S, this steel box worked well, but the top horizontal plate was bent up. In the specimen SB-L, quality of the welding between the vertical and top horizontal plate of the U-shaped steel box was not good and caused its severe damage, and the loading of this specimen was stopped at $4 \%$ drift.

\subsection{Hysteresis Characteristics}

The test results included the moments and corresponded drift angles at opening, PC yielding, and maximum moment of the specimens, are summarized in Table 2. The hysteresis characteristics of the specimens are shown in Figure 11 as the relationship between moment and rotation angle. The vertical axis shows the acting moment on the beam at the column face due to the cyclic and concentrated vertical loads and determined as:

$$
M=Q_{C Y} L-Q_{L} L^{\prime}
$$

where: $Q_{C Y}$ is the cyclic load, $L$ is the distance from the beam-end pin to the column face, $Q_{L}$ is the concentrated vertical load, and $L^{\prime}$ 
is the distance from the concentrated load to the column face. The lateral axis shows the deflection rotation, calculated as the sum of the rotation of the beam-to-column interface and the elastic deformation of the beam itself, determined as:

$$
R=R_{o}+\frac{M L}{3 E I}
$$

Where: $R$ is the deflection rotation, $R_{o}$ is the rotation of the beam section at the column face, $M$ is determined from Equation (5), $L$ is the beam length, $E$ is the Young modulus of the concrete, $I$ is the moment of inertia of the beam section.

The superimposed dashed lines on Figure 11 illustrate the calculated yielded moment strength, determined as:
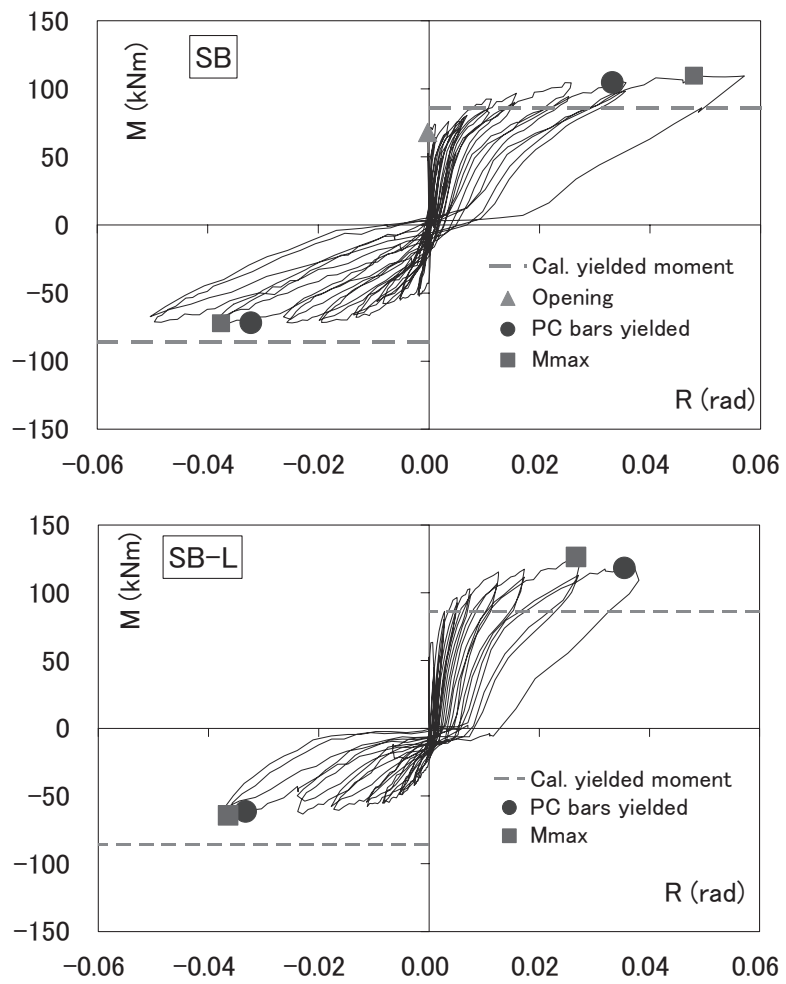

Figure 11 Moment - rotation relationship

$$
M_{y}=0.9 \frac{P_{y} D}{2}
$$

where: $P_{y}$ is the yield load of the PC steel, provided by the PC manufacturer, $D$ is the beam height.

Moment strength is calculated as:

$$
M=R \cdot d^{\prime}=F \cdot d^{\prime}
$$

where: $R$ is the reaction force of the column on to the beam

$F$ is prestressed force

$d^{\prime}$ is the moment lever arm, defined as the distance between the prestressed force and the reaction force, $d^{\prime}$ is assumed as $0.45 D=0.9 \mathrm{D} / 2$

These items are shown in the Figure 10. At yielding of PC bars,
$F=P_{y}$. Hence, yield moment strength can be calculated as: $M_{y}=$ $F \cdot d^{\prime}=P_{y} .0 .9 D / 2$

All specimens, except specimen SB-L, have successfully exceeded the drift level of $4 \%$ in negative moment and $6 \%$ in positive moment, and no fracture of $\mathrm{PC}$ bars occurred.

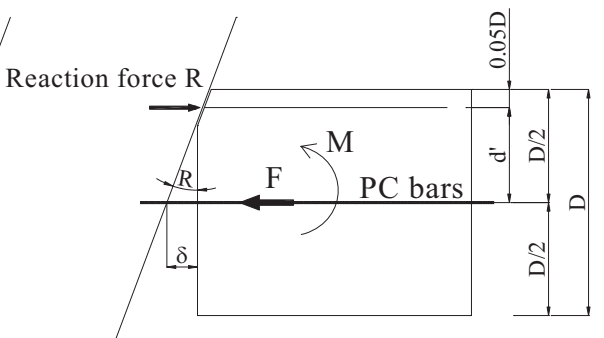

Figure 10 Definition of calculated yield moment
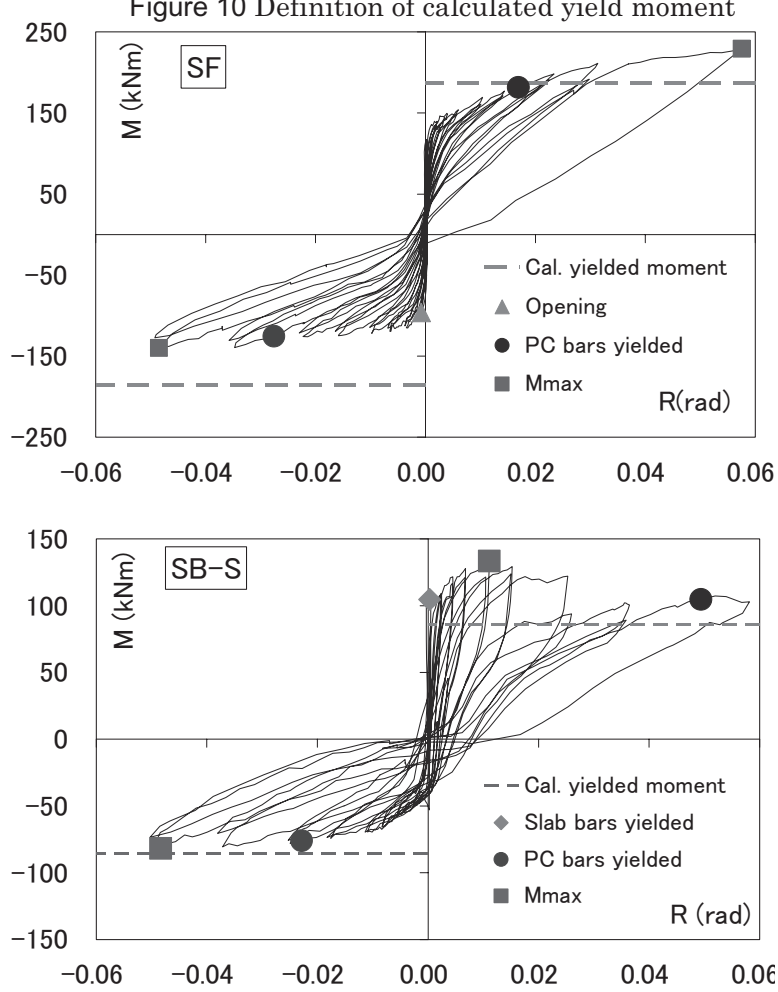

Specimen SB shows stable hysteresis behavior with nearly no strength degradation and small residual deformation. Opening at the column face occurred at the drift of $0.11 \%$ in the positive direction. The PC bars yielded at drift of $3.76 \%$ and $2.5 \%$, and the maximum moments were reached at $5.2 \%$ and $3 \%$ in positive and negative direction, respectively. The experimental yielded moment was determined as the moment at the time the PC force reached yielded value. The experimental yielded moments were $122 \%$ and $84 \%$ of the calculated ones, in positive and negative directions, respectively.

In the specimen SF, opening at the column face occurred at the drift of $0.25 \%$ in the negative direction. The PC bars yielded at drift of $2.35 \%$ and $2.34 \%$, and the maximum moments were reached at $6.0 \%$ and $4 \%$ in positive and negative direction, respectively. The experimental yielded moments were $97 \%$ and 
Table 2 Summarized test results

\begin{tabular}{c|c|c|c|c|c|c|c|c}
\hline \hline \multirow{2}{*}{ Specimens } & $\begin{array}{c}\text { Loading } \\
\text { Direction }\end{array}$ & $\begin{array}{c}M_{d} \\
(\mathrm{kNm})\end{array}$ & $R_{d}(\%)$ & $M_{y}(\mathrm{kNm})$ & $R_{y}(\%)$ & $\begin{array}{c}M_{\max } \\
(\mathrm{kNm})\end{array}$ & $R_{\max }(\%)$ & $M_{y} / M_{\text {ycal. }}$ \\
\hline \multirow{2}{*}{$\mathrm{SB}$} & + & 68.1 & 0.11 & 104.7 & 3.76 & 109.6 & 5.20 & 1.22 \\
\cline { 2 - 10 } & - & - & - & -71.9 & -2.50 & -72.2 & -3.0 & 0.84 \\
\hline \multirow{2}{*}{ SF } & + & - & - & 181.5 & 2.35 & 229.0 & 6.82 & 0.97 \\
\cline { 2 - 10 } & - & 96.4 & 0.25 & -125.6 & -2.34 & -139.9 & -4.00 & 0.67 \\
\hline \multirow{2}{*}{ SB-L } & + & - & - & 118.2 & 3.82 & 126.4 & 2.93 & 1.37 \\
\cline { 2 - 10 } & - & - & - & -61.4 & -2.72 & -64.4 & -3.00 & 0.71 \\
\hline \multirow{2}{*}{ SB-S } & + & - & - & 104.7 & 5.23 & 133.4 & 1.50 & 1.22 \\
\cline { 2 - 10 } & - & - & - & -75.9 & -1.83 & -81.8 & -3.89 & 0.88 \\
\hline \hline
\end{tabular}

Where: $M_{d}, R_{d}$ : moment and story drift when opening occurred; $M_{y}, R_{y}:$ moment and story drift at yielding; $M_{\max }$, $R_{\max }$ : maximum moment and corresponded story drift; $M_{\text {ycal }}$ : calculated yielded moment strength; “-“ : No data was recorded

$67 \%$ of the calculated ones, in positive and negative direction, respectively.

As for the specimen SB-L, the PC bars were yielded at drift of $3.82 \%$ and $2.72 \%$, and the maximum moment were reached at $2.93 \%$ and $3 \%$ in positive and negative directions, respectively. The experimental yielded moments were $137 \%$ and $71 \%$ of the calculated ones, in positive and negative direction, respectively.

In specimen SB-S, maximum moment strength was reached at drift level of $1.5 \%$, even the PC bars did not yield up to $5.23 \%$ drift in the positive direction. Maximum moment strength was about $20 \%$ larger than that of specimen SB, which was the same with specimen SB-S except without the slab. From the drift of $2 \%$, the moment strength was deteriorated, and the yielded moment strength was about $80 \%$ of the maximum moment. On the other hand, in the negative direction, the hysteresis behavior was similar with that of specimen $\mathrm{SB}$, with the yielded and maximum moments were $75.9 \mathrm{kN}$ and $81.8 \mathrm{kN}$, and attained at drift of $1.83 \%$ and $3.89 \%$, respectively. These moment strengths were almost the same with those of specimen SB. From the observation results, it can be said that the slab and slab reinforcement has considerably contributed to the moment strength and affected the behavior of the connection in the positive direction, but not in the negative direction.

In all specimens, experimental yielded moment were less than the calculated ones in the negative direction, while in the positive direction, most of the experimental yielded moment were larger than the calculated values. It can be seen from the Figure 8 that the top part of the beam near the column face suffered from heavy inelastic deformation. This deformation resulted from the combination of large compressive and shear stresses induced by the cyclic and gravity loads. As seen in Figure 12, gravity load $Q_{L}$ was transferred to the column through a strut. The force in the strut can be calculated as:

$$
F=Q_{L} / \cos \alpha
$$

In case the bottom of the beam in compression, the angle $\alpha_{1}$ is smaller than the angle $\alpha_{2}$ in case the top of the beam in compression, hence cause the force $F_{2}$ larger than $F_{1}$. This is the reason why the damage only occurred at the top part of the beam. This damage was the reason caused the moment strength could not fully develop in the negative direction. Therefore, spiral steel should be used in the upper part of the beam end to prevent it from the damage.

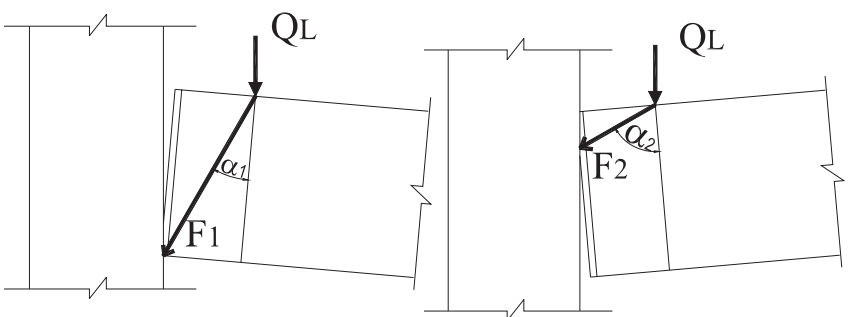

Figure 12 Explanation of damage of the top of the beam

\subsection{Beam Slip and Friction Coefficient}

The relationship between the slip of the beam at peak drift angle and the story of all specimens is shown in Figure 13. The relationship of the beam slip and drift of the specimen SF is shown in the Figure 14, while the relationship between the friction coefficient and story drift of the specimen SF is shown in Figure 15, and the relationship between the beam slip and friction coefficient is shown in Figure 16. From the Figure 13, it can be seen that the slip of the beam of specimen SF (without shear bracket) was much larger than those of others with shear bracket. The slips of the beam at $4 \%$ drift in the specimens SB, SB-L, and SB-S were $8.9 \mathrm{~mm}, 12.9 \mathrm{~mm}$, and $9.7 \mathrm{~mm}$, respectively. The cause of the slip in the specimens SB, SB-L, and SB-S was the deformation of the top of the shear bracket and the bent up of top horizontal plate of the inverted U-shaped steel box. The slip of the beam in the specimen $\mathrm{SF}$ at $4 \%$ drift was $21.5 \mathrm{~mm}$; even though this specimen was designed follow the guidelines of AIJ with friction coefficient of 0.5 . Figure 14 shows that the beam slip increased gradually with the story drift. The slip mostly occurred when the drift was around $+1 \%$ at each cycle, when the ratio of the beam shear force to the PC force $\left(Q_{B} P_{P C}\right)$ became largest. Figure 16 shows the beam slip and the $Q_{B} / P_{P C}$ ratio relationship. The dashed line expresses the upper bound of the ratio at each loading cycle, and illustrates the friction coefficient $\mu$. It can be seen that, beam slip occurred when the value of $\mu$ was around 0.45 , smaller than the design value of 0.5. In this study, the gravity load and cyclic load was applied simultaneously. Under the effect of cyclic load, the surface of the beam at the column interface was damaged and this may be the reason for the small value of friction coefficient. 


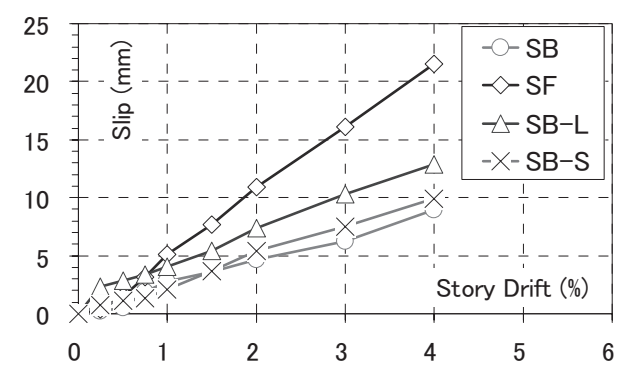

Figure 13 Beam slip - story drift relationship of all specimens

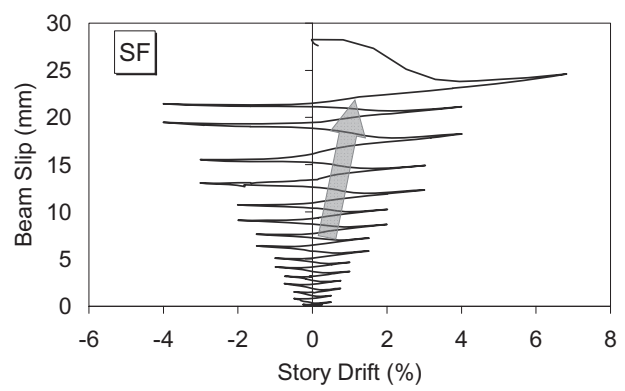

Figure 14 Beam slip - story drift relationship, SF

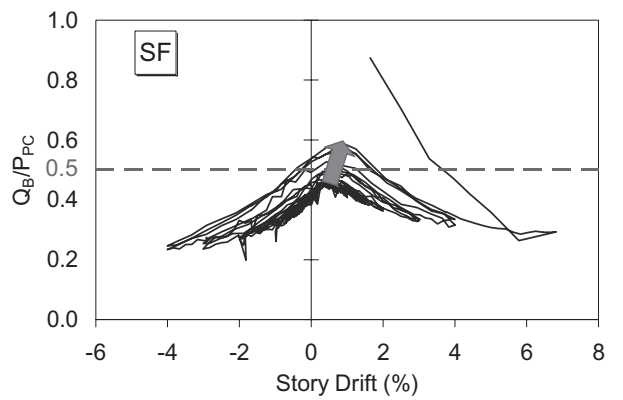

Figure 15 Beam shear force/PC force - story drift relationship, SF

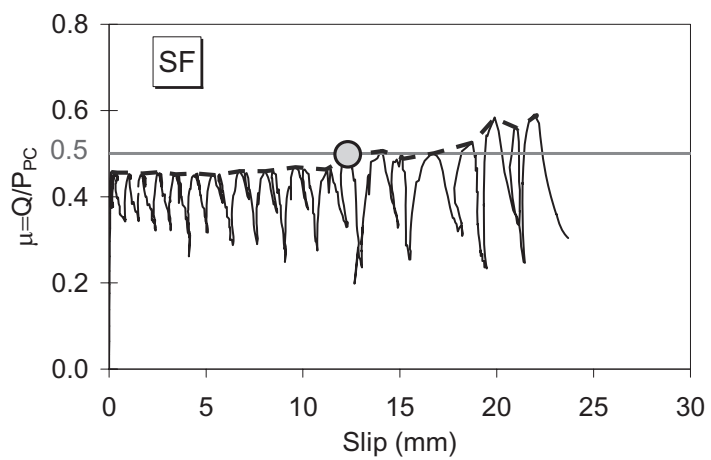

Figure 16 Beam slip - friction coefficient relationship, SF

\subsection{Deflection ratio of the elements.}

The relationship between the deflections ratio of the elements and the story drift of the specimens SB, SF, and SB-L are shown in Figure 17 (no data was recorded for the specimen SB-S). The vertical axis expresses the deflection ratios of the column, beam, and the beam-to-column interface opening rotation to the total deflection. These deflection components were measured by the measuring system shown in Figure 3. The average values in positive and negative directions of the deflection ratio of the beam-to-column interface at $0.25 \%$ drift are $60.9 \%, 41.8 \%$, and
$62.1 \%$ for the specimens SB, SF, and SB-L, respectively. These values increased up to $90 \%, 83.7 \%$, and $89.8 \%$ for the specimens $\mathrm{SB}, \mathrm{SF}$, and SB-L, respectively at $4 \% \operatorname{drift}$ ( $3 \%$ for specimen SB-L). It can be seen that, at large drift angles, total deflection of the specimens mainly contributed by the deflection of the beam-to-column interface. Deflection ratio of the beam-to-column interface of the specimens SB and SB-L were larger compared to that of the specimen SF, meaning that less deformation occurred to the beam and column elements. This is also one advantage of the connection with shear bracket over the one without shear bracket.
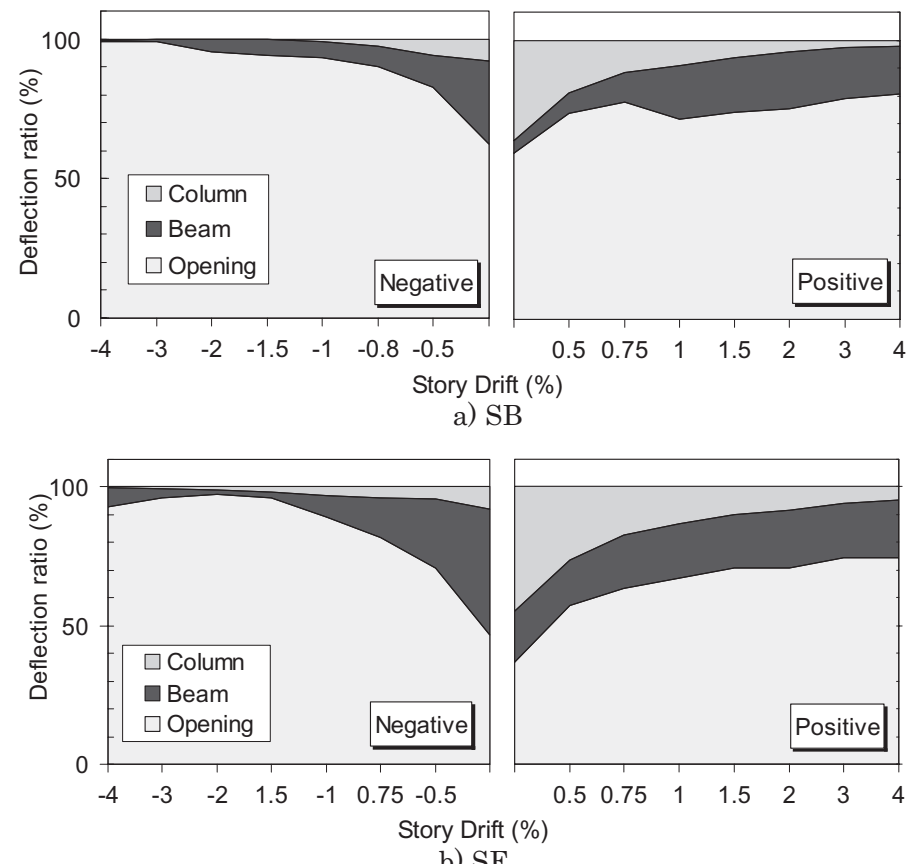

b) $\mathrm{SF}$

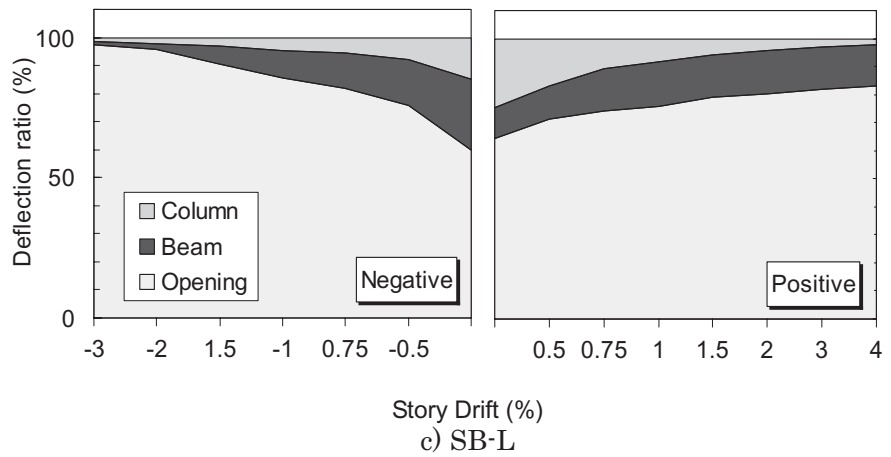

Figure 17 Deflection ratios of the specimens SB, SF, SB-L

\subsection{Variation of prestressing force}

In this section, variation of prestressing force of the PC bars of specimen SF was discussed. Average initial prestressing force at applying time was $0.77 \mathrm{P}_{\mathrm{y}}$. The prestressing force at the start of the test was $0.73 \mathrm{P}_{\mathrm{y}}$. This prestressing force was slightly larger than required value of $0.7 \mathrm{P}_{\mathrm{y}}$. Prestressing force lost approximately $4.8 \%$ by 27 days. Prestressing force fluctuated during the test. Variation of prestressing forceof the specimen SF is shown in Figure 18. 


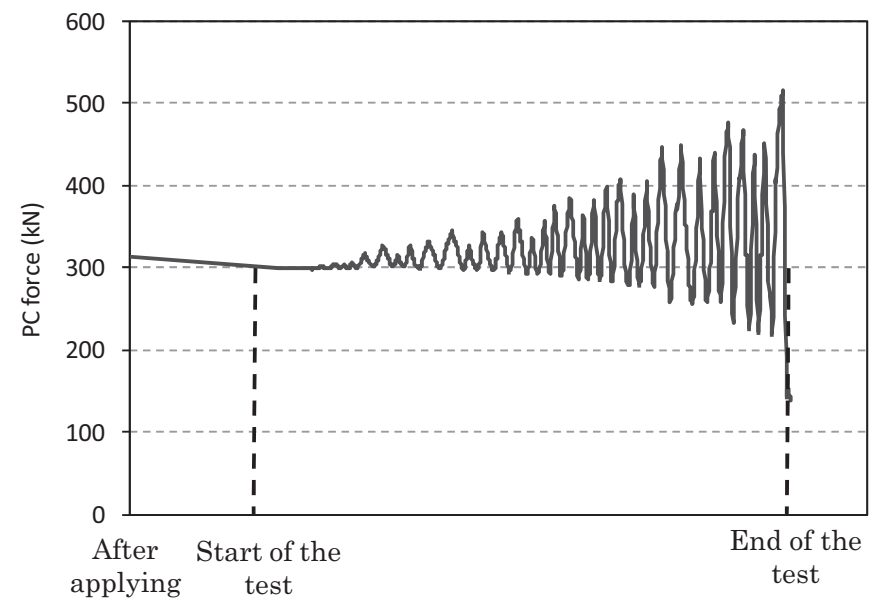

Figure 18 Variation of PC force, specimen SF

\section{CONCLUSIONS AND RECOMMENDATIONS}

\subsection{Conclusions}

From the test results, following conclusions can be drawn. 1) The basic specimen with shear bracket (SB) expressed good hysteresis behavior with small residual deformation and small deflection ratios of the beam and column element, although some deformation still occurred to the bracket.

2) Except specimens SB-L, other specimens successfully exceeded the story drift of $4 \%$. No decay of the strength was observed, with the exception of in the positive direction of the specimen SB-S. Few cracks were recorded, especially in the column and joint, especially in specimens which the shear bracket was applied.

3) The specimen without shear bracket experienced large beam slip, and the slip occurred at the friction coefficient of 0.45 , smaller than design value of 0.5. Damage of the surface of the beam at the column interface under the effect of cyclic load may be the reason for the small value of friction coefficient.

4) Excessive crush of slab concrete occurred together with the fracture of the slab reinforcement caused the deterioration of the strength and resulted in large residual deformation of the connection in the positive direction. Therefore, the slab should be completely separated from the column and spandrel beam.

\subsection{Recommendations}

From the test results, following recommendations are proposed: 1) The spiral steel should be used in the top of the beam end at the column face to confine the concrete and avoid compressive failure of the concrete.

2) The design of the shear bracket and inverted U-shaped steel box should be modified to prevent the deformation of these parts under the action of very large gravity load and cyclic load.

\section{ACKNOWLEDGEMENT}

This research was conducted as a part of the project to develop new type of high-rise R/C office building, organized in Building Contractors Society, led by Prof. Hitoshi Shiohara. The financial support of Ministry of Land, Infrastructure, Transport, and Tourism for this research is gratefully acknowledged.

\section{REFERENCES}

1) Architecture Institute of Japan, "Standard for Structural Design and Construction of Precast Concrete Structures", 2003, in Japanese.

2) Architecture Institute of Japan, "Standard for Structural Design and Construction of Prestressed Concrete Structures", 1998, in Japanese.

3) Prestressed Concrete Institute, "PCI Design Handbook", 6 th $^{\text {th }}$ Edition, 2004

4) M. J. N. Priestley, and J. Tao, "Seismic Response of Precast Prestressed Concrete Frames with Partially Debonded Tendons," PCI JOURNAL, Vol. 38, No. 01, January-February 1993 , pp. 58-69.

5) W. C. Stone, G. S. Cheok, and J. F. Stanton, "Performance of Hybrid Moment-resisting Precast Beam-Column Concrete Connections Subjected to Cyclic Loading," ACI Structural Journal, V92, No.2, March-April 1995, pp 229-249.

6) M. J. N. Priestley, and G. A. MacRae, "Seismic Tests of Precast Beam-to-Column Joint Subassemblages with Unbonded Tendons", PCI JOURNAL, Vol. 41, No. 01, January-February 1996, pp. 64-81.

7) S. Pampanin, "Emerging Solution for High Seismic Performance of Precast/Prestressed Concrete Buildings," Journal of Advanced Concrete Technology, Vol. 03, No. 02, June 2005, pp 207-223.

8) D. T. Thinh, K. Kusunoki, and A. Tasai, "Study on a New Precast Post-Tensioned Beam-Column Joint System for Rapid Erection and Improved Resiliency", JCI Annual Convention, Vol. 30, No. 03, July 2008, pp 385-390.

9) I. Kawakubo, T. Ishioka, T. Nishimura, Y. Hosoi, N. Aragane, M. Kanagawa, S. Takeda, "Development of a Large-Span Precast Concrete Structural System with Ease of Construction Using Prestressed Connections, Part 10 Verification by Dynamic Response Analysis (1)", AIJ Annual Convention, September, 2008, pp 669-670.

（2008年 9 月 10 日原稿受理，2009年 3 月25日採用決定） 